\title{
Inverse design methodology to optimize sensible thermal energy storage systems working as rectifiers
}

\author{
Tiago Haubert Andriotty (iD) | Paulo Smith Schneider (iD) | Letícia Jenisch Rodrigues (iD
}

Department of Mechanical Engineering, Federal University of Rio Grande do Sul, Porto Alegre, Brazil

\section{Correspondence}

Tiago Haubert Andriotty, Department of Mechanical Engineering, Federal

University of Rio Grande do Sul, Porto

Alegre, Brazil.

Email: tiago.haubert@ufrgs.br

\section{Funding information}

Coordenação de Aperfeiçoamento de Pessoal de Nível Superior, Grant/Award Number: Doctorship grant; CNPq (Brazilian National Council for Scientific and Technological Development), Grant/ Award Number: CNPq-PQ 305357/2013-1

\begin{abstract}
Summary
The main goal of this paper is to present a methodology to achieve the optimal design of a sensible thermal energy storage system (T3S) working as a thermal rectifier. The system was composed by the heat storage material (HSM), distributed in a set of flat parallel plates, and the working fluid, both modeled by a simplified lumped element model (LEM). The ratio of operational outlet temperature range to source temperature oscillation is defined as the designed rectifying duty. Optimization procedure combines a one-factor-at-a-time (OFAT) and line search strategies in order to find optimal T3S design that satisfies the designed rectifying duty with the minimum HSM mass. The inverse design philosophy is applied to the optimal results to generalize the T3S dynamic behavior as functions fitting curves of the number of transfer unit (NTU) and the time constant $\tau$. These fitting curves can be used to identify T3S geometric parameters, HSM thermal properties, fluid inlet conditions, among others, which guarantee the outlet fluid temperature to be found within the operational range with the minimum HSM mass. A three step-by-step sequence design methodology is presented and detailed, based on design charts from the NTU and $\tau$ correlations. The proposed design methodology is able to find the optimal plate length $L$, plate thickness $e_{s}$, and plate distance $e_{f}$ that satisfies the designed rectifying duty for three test cases. These optimal T3S designs are simulated in a computer fluid dynamics (CFD) code, with deviations below $1.5 \%$ between the designed rectifying duty and the one simulated. With the proposed approach, several design solutions or configurations can be found for T3S operating as a thermal rectifier based on NTU and $\tau$ fitting curves submitted to a sinusoidal cyclic temperature input and with constant and uniform HSM and fluid properties.
\end{abstract}

\section{KEYWORDS}

cyclic heat storage, design charts, lumped element model, optimization, sensible thermal energy storage, thermal rectifier

\section{1 | INTRODUCTION}

Sensible thermal energy storage systems (T3Ss) must be accessed according to their storage material and application. Literature review indicates previous work on design methodologies connecting storage system characteristics to operational condition, like the one from Klein et al, ${ }^{1}$ which proposed graphical design tools for 
domestic solar systems, known as f-chart, with air or water as thermal fluids.

Schmidt and Szego ${ }^{2}$ and Schmidt et $\mathrm{al}^{3}$ proposed storage systems based on flat parallel plates, by modeling the working fluid as a transient 1D capacitive flow and the solid media as a transient 2D storage material. Results were presented in diagrams oriented to system design by selecting material thickness and length, plate distance, operational fluid temperatures, and heat storage.

A design method for concentrated solar power (CSP) plants was proposed by Li et al, ${ }^{4}$ based on similarity analysis, which was able to generalize system devices, such as water tanks, rock beds, and imbedded tubes into heat storage materials (HSMs). Results were once more presented in graphical form, relating system geometry to load and unload times.

Jian et $\mathrm{al}^{5}$ modified a lumped model by using Laplace transforms to solve several T3S configurations, whose accuracy was verified in respect to a real scale concrete prototype storage unit and showed reasonable agreement. A T3S design procedure was presented, in order to reduce the system costs.

Gude et $\mathrm{al}^{6}$ worked on low-temperature $\left(40-50^{\circ} \mathrm{C}\right)$ water desalinization systems based on solar collectors with sensible heat storage, solved by a semianalytical model. The authors submitted the system to a 3-week clear sky weather sequence and a 3-week weather sequence with one cloudy day per week. Freshwater production rate for a nonstorage system was $50 \%$ smaller on cloudy weather compared with the clear sky one, but differences were found to be $8 \%$ with a $1-\mathrm{m}^{3} \mathrm{HSM}$ and $5 \%$ for $3-\mathrm{m}^{3} \mathrm{HSM}$.

Darzi et $\mathrm{al}^{7}$ simulated the use of phase change materials (PCMs) to reduce the air-conditioning consumption in buildings, by storing low-level energy during nighttime. The system effectiveness was proven for short operation periods, but it rapidly decreased for longer periods.

Zanganeh et $\mathrm{al}^{8}$ proposed a hybrid sensible and latent packed bed heat storage system. The system was modeled by a transient one-dimensional formulation and submitted to an air inlet flow with cyclic temperature. The PCM was placed in the system outlet in order to stabilize the fluid temperature, and its minimum dimension represented only $1.33 \%$ of the total volume, which was less than $5 \%$ of the total storage energy in the system, mainly based on sensible storage.

Soda and Beyene ${ }^{9}$ assessed different PCMs to be used in an organic Rankine cycle. The authors emphasized that the advantage of latent heat storage in respect to sensible one relies on its capacity to deliver constant fluid output temperature, a desirable quality whenever steady-state regimes are to be performed, but highlighted handicaps as inflammability, hysteresis, and cost.
Rezaie et $\mathrm{al}^{10}$ studied the T3S transient behavior along charging and discharging duties. The T3S was modeled as a fully mixed storage system, neglecting temperature gradients within the storage material and capable of recovering the entire input energy flow rate. Results showed that the increase in discharging temperature could be met by adjusting both the input and output energy rates associated to the working fluid.

Ghoreishi-Madiseh et $\mathrm{al}^{11}$ studied deep mine thermal air conditioning. Heat stored in a rock pit along summer days was employed during winter, as a sort of seasonal thermal rectifier. Volume average theory was used to model a 3D unsteady porous media for a long period of 10 years and compared with real data from the Creighton mines in Canada. T3S was able to save up to US\$ 437000 per year and reduce 8862 tons of carbon emissions by avoiding artificial conditioning systems.

Demir and Dincer ${ }^{12}$ proposed the integration of a thermal energy storage to a solar energy system for fresh water and electricity production. The system was based on a Rankine cycle driven by solar energy stored at a molten salt medium coupled to a multistage flash process for water desalination. The authors found that the highest exergy destruction and heat losses were identified to occur at the solar receiver and the steam generator, in contrast to lower ones for the storage tanks.

Whenever the storage system operates under continuous regime, the inlet energy brought by the working fluid is partially storage by the system material and simultaneous transferred to along its pathway, which can be considered as a rectification process. As in solar dryers, the input energy during daytime is stored to be recovered during the night period, but that process also helps to stabilize the outlet fluid flow temperature to the drying chamber.

Literature review showed that although sensible heat storage is less energy intensive compared with PCM, it displays advantages such as lower HSM cost, no inflammability issues, no hysteresis, lower environmental impact, and is easier to be installed or linked to building facilities. ${ }^{13-16}$ Moreover, some methods evaluate T3S performance by employing complex and time-consuming numerical models, ${ }^{11}$ and some are based on try-and-error method $^{4,8}$ or evaluate the performance of specific system configuration $^{6}$, not taking into account the minimization of the HSM mass nor the more appropriate system geometry. It is worth noticing that some optimization methodologies $^{5}$ are not generic and need to be processed whenever the system parameters are changed.

The main goal of this work is to present a methodology to optimal design of sensible heat storage systems working as thermal rectifiers when submitted to sinusoidal cyclic outside air temperature, based on the advantages 
of sensible thermal storage, together with the limitations of the current design methodologies.

\section{2 | THE LUMPED ELEMENT MODEL (LEM) APPLIED TO THE T3S RECTIFIER}

\section{1 | Modeling}

The T3S presented in this work was meant to operate as a thermal rectifier, designed to soften temperature oscillations from cyclic sources, as depicted in Figure 1.

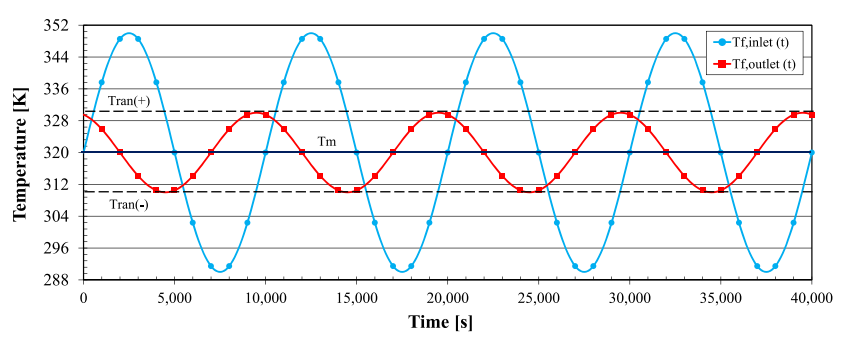

FIGURE 1 Rectified outlet air temperature (square dot) of a sensible thermal energy storage system (T3S) fed by a cyclic thermal source (circle dot) [Colour figure can be viewed at wileyonlinelibrary.com]

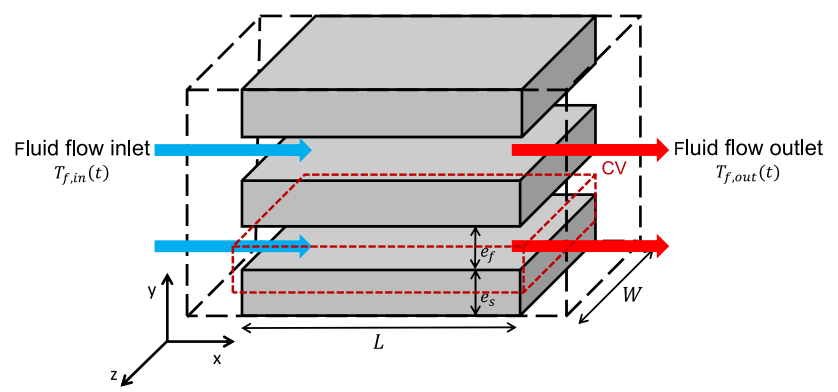

FIGURE 2 Schematic view of the sensible thermal energy storage system (T3S) [Colour figure can be viewed at wileyonlinelibrary.com]
The system was composed by the HSM, distributed in a set of flat parallel plates, and the working fluid, as depicted in Figure 2.

T3S modeling was implemented to a reduced $2 \mathrm{D}$ region (Figure 3), whose domain was limited to half-flat plate $e_{s} / 2$ and half channel $e_{f} / 2$ height, length $L$, and unitary width $W$. The symmetric $2 \mathrm{D}$ region was divided in $n$ independent sections, with individual length $L / n$, for the sake of keeping the model accuracy. ${ }^{17-22}$

Energy balances were written for the coupled solid and fluid control volumes for a given $j$ section in order to calculate the system outlet fluid temperature $T_{f}, j(t)$. Working fluid thermal capacitance, defined by the product $M_{f} c_{p, f}$, is much smaller than the one from HSM, assuming it as noncapacitive. ${ }^{18}$ The new system was solved for $T_{f, j}(t)$ by applying the separation of variables technique, as presented in an earlier work, ${ }^{17}$ given by the following equation system.

$$
\begin{aligned}
T_{s, j}(t)= & T_{s, j}(t-\Delta t)-\left[1-\exp \left(-\frac{\bar{h}_{j} A_{s, j}}{c_{p, s} \rho_{s} V_{s, j}} \Delta t\right)\right] \\
& \left(T_{s, j}(t-\Delta t)-\bar{T}_{f, j}(t)\right), \\
T_{f, j}(t)= & T_{s, j}(t)-\left[\exp \left(-\frac{\bar{h}_{j} A_{s, j}}{\dot{m} c_{p, f}}\right)\left(T_{s, j}(t)-T_{f, j-1}(t)\right)\right] .
\end{aligned}
$$

Symmetry conditions were imposed to the T3S upper and lower boundaries, leaving heat transfer to occur along the fluid interface with the HSM surface and the mass flow connection to the adjacent sections. The time constant $\tau$ and the number of transfer unit (NTU) ${ }^{23}$ were identified on these equations, rewritten as follows:

$$
\begin{aligned}
T_{s, j}(t)= & T_{s, j}(t-\Delta t)-\left[1-\exp \left(-\frac{\Delta t}{\tau}\right)\right] \\
& \left(T_{s, j}(t-\Delta t)-\bar{T}_{f, j}(t)\right),
\end{aligned}
$$

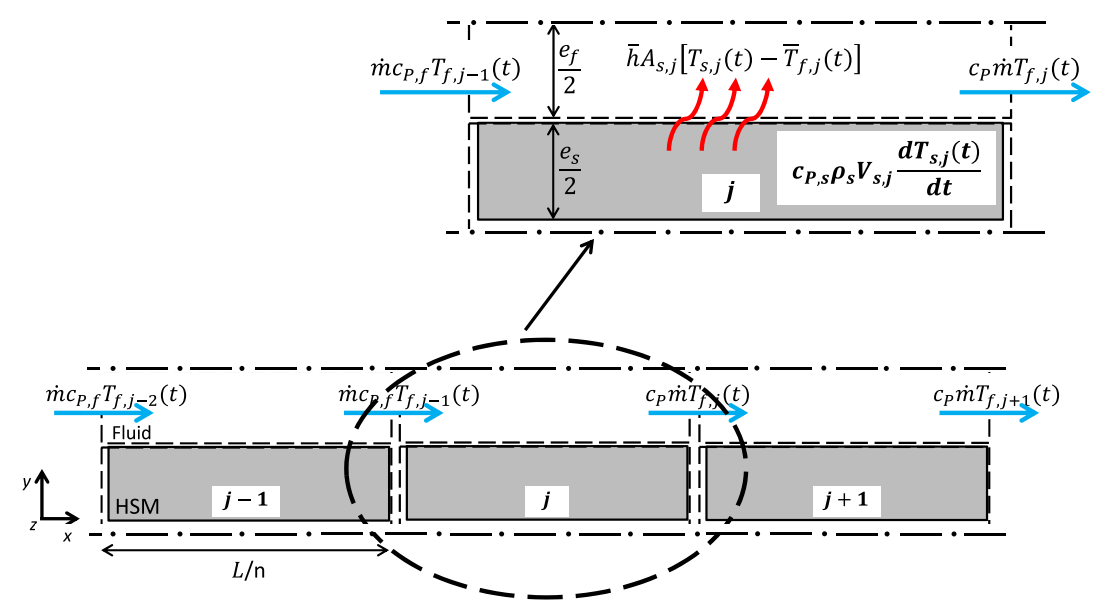

FIGURE 3 Scheme of the symmetric $2 \mathrm{D}$ region with three independent sections of length $L / n$ [Colour figure can be viewed at wileyonlinelibrary.com] 


$$
T_{f, j}(t)=T_{s, j}(t)-\left[\exp \left(-N T U_{j}\right)\left(T_{s, j}(t)-T_{f, j-1}(t)\right)\right],
$$

with $\tau=\frac{c_{p, s} \rho_{s} V_{s, j}}{h A_{s, j}}$ and $N T U_{j}=\frac{N T U}{n}=\frac{\bar{h} A_{s, j}}{\dot{m} c_{p, f}}$.

The average fluid temperature $\bar{T}_{f, j}(t)$, the last term in Equation 3, was expressed as the average value between the sections $j$ and $j-1$, as follows:

$$
\bar{T}_{f, j}(t)=\frac{T_{f, j-1}(t)+T_{f, j}(t)}{2} .
$$

The set of Equations 3 to 5 assembles the LEM used to model the T3S. The inlet working fluid temperature $T_{f \text {, in }}$ was given by the following sinusoidal function:

$T_{f, \text { in }}(t)=T_{f, \operatorname{in}(-)}+\left[1+\operatorname{sen}\left(\frac{\pi t}{\frac{\beta}{2}}\right)\right]\left(\frac{\left[T_{f, \operatorname{in}(+)}-T_{f, \operatorname{in}(-)}\right]}{2}\right)$,

with $T_{f}$, in(+) and $T_{f}$, in(-) the function upper and lower limits and $\beta$ its cycle period.

It is worth noticing that Hughes ${ }^{24}$ modeled sensible thermal storage systems with the $\varepsilon$-NTU approach. HSM temperature behavior was taken as linear for each time step, whereas LEM method applied in the present paper assumed it to behave exponentially, like classic lumped models. $^{23,25}$

\section{2 | LEM implementation}

Simulation was run for a 10 -second time step $\Delta t$ and for the original length $L$ divided into 100 sections. The LEM was performed to find the fluid outlet temperature $T_{f \text {, out }}(t)$ at the last section $N$ by following these six steps.

1. Calculate the T3S fluid inlet temperature $T_{f \text {, in }}(t)$ at time $t$ (Equation 6).

2. Perform the fluid temperature $T_{f, j}(t)$ (Equation 4) calculation at the outlet of the $j$ th section at time $t$ with the HSM temperature $T_{s, j}(t-1)$ from the prior time $t-1$ (Equation 3).

3. Perform arithmetic average fluid temperature $\bar{T}_{f, j}(t)$ (Equation 5) from $T_{f, j-1}(t)$ and $T_{f, j}(t)$ for the $j$ th section at time $t$.

4. Perform the HSM temperature at time $t$ (Equation 3) based on the temperature $\bar{T}_{f, j}(t)$ (Eq. 5) from step 3.

5. Repeat steps 2 to 4 for all $j$ sections for time $t$.

6. Repeat steps 1 to 5 for the next time step and carry on the simulation till the end of the total time set to find the fluid outlet temperature $T_{f}$, out $(t)$ for the problem.
Results were assessed for a quasi-steady regime and reached for a periodic temperature fluctuation around a constant mean value $T_{m}$. Calculation was implemented in a Matlab code.

\section{3 | INVERSE DESIGN APPROACH}

Inverse design approach consists in determining the system parameters by defining its response behavior, instead of leaving that behavior as the consequence of a direct calculation. In the present work, this philosophy was chosen to propose a design methodology for the T3S with the aim to find the minimal HSM mass that satisfies the constraint stablished in Equation 7.

$$
T_{\operatorname{ran}(-)}<T_{f, \text { out }}(t)<T_{\operatorname{ran}(+)} .
$$

A sensible storage system, with constant and uniform thermophysical properties, submitted to a sinusoidal thermal excitation gives a dynamic sinusoidal response, expressed as a function of the system dimensionless operational temperature $\theta_{\text {oper }}$, given by

$$
\theta_{\text {oper }}=\frac{\left|T_{m}-T_{f, \text { out }(+)}\right|}{\left|T_{m}-T_{f, \text { in }(+)}\right|} .
$$

Equation 8 can range from $\theta_{\text {oper }}=1$, meaning that there is no heat transfer between the HSM and the working fluid, as $T_{f \text {, out }(+)}=T_{f \text {, in(+), }}$, to $\theta_{\text {oper }}=0$ meaning that $T_{f \text {, out (+) }}=T_{m}$. When $T_{f, \text { out (+) }}=T_{\operatorname{ran}(+)}$, the T3S reached its designed rectifying duty, expressed by Equation 9.

$$
\theta_{\text {oper }}=\theta_{\text {ran }(+)}=\frac{\left|T_{m}-T_{\text {ran }(+)}\right|}{\left|T_{m}-T_{f, \text { in }(+)}\right|} .
$$

Previous assessments concerning the T3S depicted in Figure 2 were presented by Andriotty. ${ }^{17}$ The system was optimized to find simultaneously the minimum HSM mass, the best plate length and plate distance that satisfied the rectifying duty $\theta_{\operatorname{ran}(+)}=0.133$, for several working fluid mass flow rates. Three major conclusions have been taken from that work:

1. The minimum HSM mass and the $h A_{s}$ product displayed direct correlations, leading to optimum values for NTU and $\tau$, independent from fluid mass flow rate. The plot of $\theta_{\text {oper }}$ versus system NTU for different HSM mass Ms (Figure 4) allows identifying the minimal value for the dimensionless operational parameter $\theta_{\text {oper }}$ of each system and graphically indicates the system that satisfies the desired operational condition. 


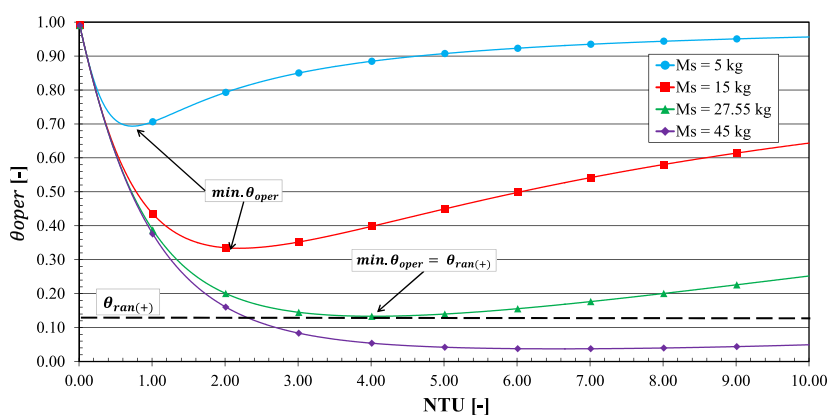

FIGURE 4 Dimensionless operation temperature as a function of NTU for different HSM mass ( $\dot{m}=0.001 \mathrm{~kg} / \mathrm{s}$ and $\beta=20000 \mathrm{~s}$ ). [Colour figure can be viewed at wileyonlinelibrary.com]

Smaller NTU values led to lower heat transfer rates, which means that the outlet fluid temperature is almost the same as the inlet. For greater NTU values, heat transfer is more intense and consequently more difficult to control ${ }^{17}$.

2. The optimal NTU, the one that satisfies the minimum HSM mass, is in fact an infinite combination of superficial area $A_{s}$ and heat transfer coefficient $\bar{h}$. The $A_{s}$ and $\bar{h}$ combinations can be expressed as a Pareto front ${ }^{26-28}$ as displayed in Figure 5.

All values along that Pareto front are system Pareto optimal. Any outside value means that the HSM mass would not guarantee the maximal T3S rectifying capacity, as presented in Figure 4.

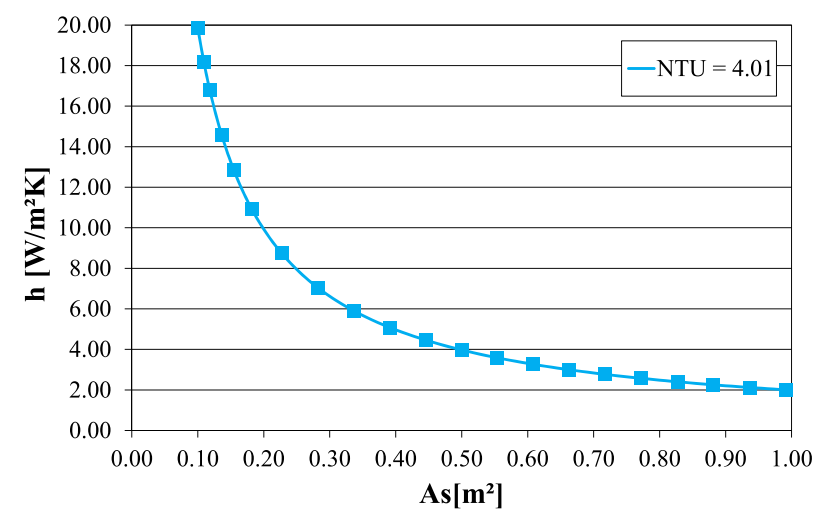

FIGURE 5 Heat transfer coefficient $\bar{h}$ and superficial area $A_{s}$ as a Pareto front for a T3S with NTU $=4.01(\dot{m}=0.001 \mathrm{~kg} / \mathrm{s})[$ Colour figure can be viewed at wileyonlinelibrary.com]
3. Same behavior can be identified in respect to the optimal time constant $\tau$, with common dependent parameters in respect to NTU.

Based on those behaviors, a T3S design methodology was proposed as a function of the combination of the system NTU, time constant $\tau$, and $\theta_{\text {ran(+) }}$. NTU and HSM mass were chosen as optimization parameters, and $\tau$ can be obtained from NTU results by post processing.

Air and HSM properties were taken as constant and uniform (Table 1). It is worth noticing that HSM thermal conductivity is not taken into account on the LEM approach.

The one-factor-at-a-time (OFAT) ${ }^{29}$ strategy was used to individually analyze mass flow rate $\dot{m}$, period $\beta$, and the designed rectifying duty $\theta_{\operatorname{ran}(+)}$, displayed in Table 2 , organized in three procedures.

Calculations were performed for different increments (Table 2), following the line search strategy ${ }^{30,31}$ in respect to the $p$ procedures in order to assemble the $R_{p}$ matrices, as depicted in Figure 6. The solutions for each level $i$ of each procedure $p$ from the $R_{p}$ matrices are to be presented in the next section.

\section{4 | RESULTS}

\section{1 | Overall results}

Tables 3-5 present results for NTU, $M s_{\min }$, and $\tau$ obtained with procedures 1 to 3 , respectively.

Mass flow rate and the HSM minimum mass displayed a linear dependency, whereas NTU and $\tau$ can be considered as constant. The maximum $0.5 \%$ deviation from the optimal NTU and $\tau$ values can be considered as numerical fluctuations, due to the line search strategy and parameters bounds (Table 2).

Both $M s_{\min }$ and $\tau$ displayed a linear dependency with period $\beta$, while NTU can be considered as constant. Figure 7 brings the time evolution of the fluid outlet temperature $T_{f}$, out and the half plate length $(L / 2)$ temperature predicted for procedures and levels $(p=1 ; i=1)$, $(p=1 ; i=2)$, and $(p=2 ; i=1)$.

TABLE 1 Properties of air and HSM at $320 \mathrm{~K}^{\mathrm{a}}$

\begin{tabular}{|c|c|c|c|c|c|}
\hline & $\begin{array}{l}\text { Density } \rho \\
\left(\mathrm{kg} / \mathrm{m}^{3}\right)\end{array}$ & $\begin{array}{l}\text { Specific Heat } c_{p} \\
\left(\mathrm{~J} \mathrm{~kg}^{-1} \mathrm{~K}^{-1}\right)\end{array}$ & $\begin{array}{l}\text { Dynamic Viscosity } \mu \\
\left(\mathrm{kg} \mathrm{m}^{-1} \mathrm{~s}^{-1}\right)\end{array}$ & $\begin{array}{l}\text { Prandtl Number } \\
\operatorname{Pr}(-)\end{array}$ & $\begin{array}{l}\text { Thermal Conductivity } \\
k\left(\mathbf{W} \mathbf{m}^{-1} \mathrm{~K}^{-1}\right)\end{array}$ \\
\hline Fluid (Air) & 1.103 & 1008 & 1.949 E-5 & 0.705 & 2.785 E-2 \\
\hline
\end{tabular}

Abbreviations: HSM, heat storage material.

${ }^{\mathrm{a}}$ Bergman et al. ${ }^{25}$ 
TABLE 2 T3S parameters bounds for the proposed procedures $\left(T_{m}=320 \mathrm{~K}\right)$

\begin{tabular}{|c|c|c|c|c|c|}
\hline Procedures $p$ & Input & Minimum & Maximum & Increment & Levels $i$ \\
\hline $1^{\mathrm{a}}$ & $\dot{m}(\mathrm{~kg} / \mathrm{s})$ & 0.001 & 0.005 & 0.001 & 5 \\
\hline 2 & $\beta(s)$ & 4000 & 20000 & 4000 & 5 \\
\hline 3 & $\theta_{\operatorname{ran}(+)}(-)$ & 0.066 & 0.933 & 0.066 & 14 \\
\hline \multicolumn{6}{|l|}{ Optimized variables } \\
\hline \multicolumn{6}{|l|}{ Related restrictions } \\
\hline 1 & \multicolumn{5}{|c|}{$\beta=20000 \mathrm{~s}$ and $\theta_{\mathrm{ran}(+)}=0.133$} \\
\hline 2 & \multicolumn{5}{|c|}{$\dot{m}=0.001 \mathrm{~kg} / \mathrm{s}$ and $\theta_{\mathrm{ran}(+)}=0.133$} \\
\hline 3 & \multicolumn{5}{|c|}{$\dot{m}=0.001 \mathrm{~kg} / \mathrm{s}$ and $\beta=20000 \mathrm{~s}$} \\
\hline
\end{tabular}

Abbreviations: HSM, heat storage material; NTU, number of transfer unit; T3S, sensible thermal energy storage system.

${ }^{\mathrm{a}}$ Andriotty. ${ }^{17}$

FIGURE 6 Minimum heat storage material (HSM) mass search algorithm based on the one-factor-at-a-time (OFAT) approach for mass flow rate $\dot{m}$, period $\beta$, and the designed rectifying duty $\theta_{\operatorname{ran}(+)}$ for a range of HSM mass $M_{s}$ and number of transfer unit (NTU) values

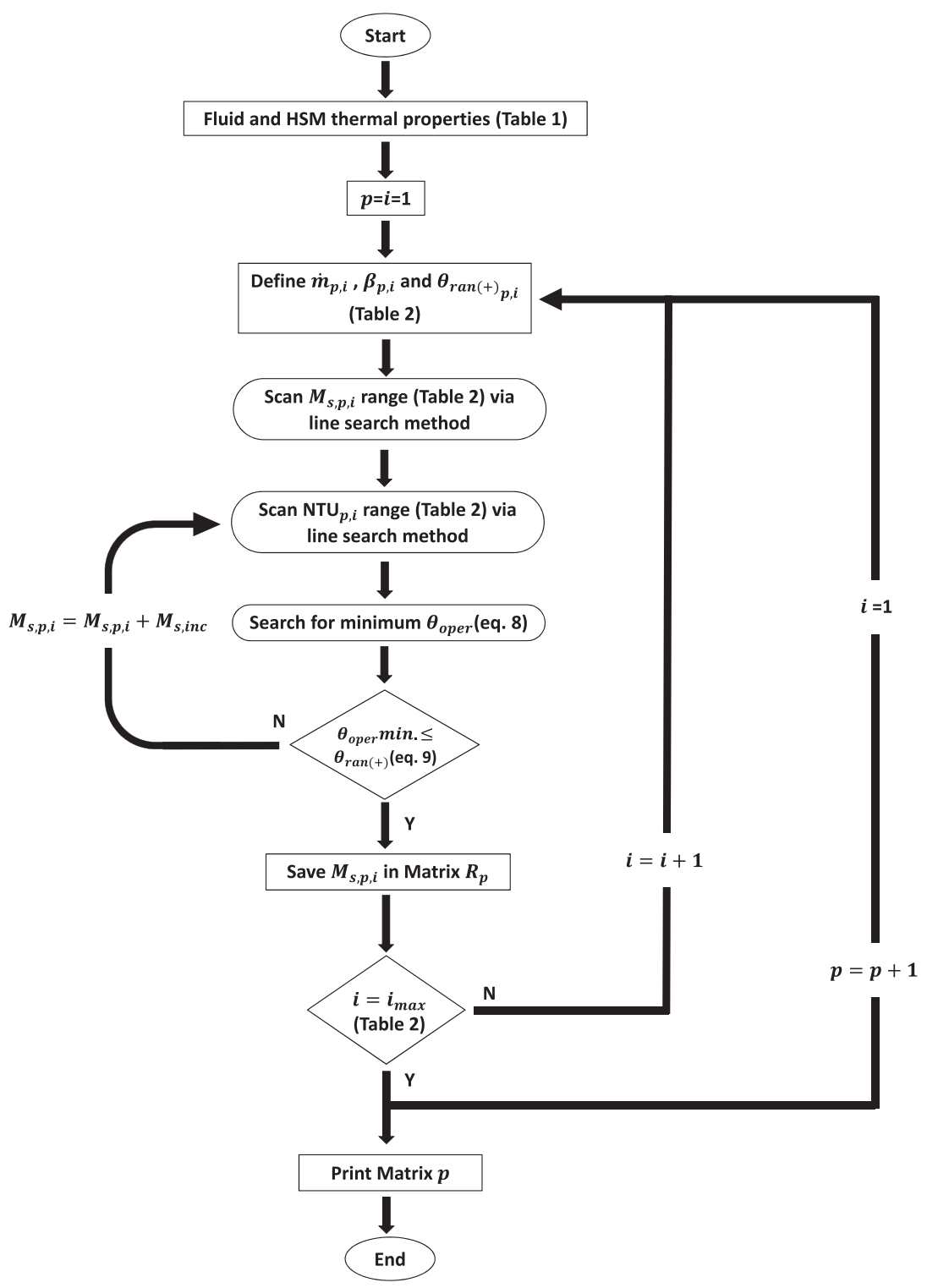


TABLE 3 NTU, $M s_{\min }$, and $\tau$ for five levels of mass flow rate $\dot{m}$ (procedure $p=1$ )

\begin{tabular}{lllll} 
Level & $\begin{array}{l}\text { Mass Flow Rate } \\
\dot{\boldsymbol{m}}\left(\mathrm{kg} \mathrm{s}^{\mathbf{- 1}}\right)\end{array}$ & NTU (-) & $\boldsymbol{M s}_{\text {min }}(\mathbf{k g})$ & $\boldsymbol{\tau}\left(\mathbf{1 0}^{\mathbf{3}} \mathbf{s}\right)$ \\
1 & 0.001 & 4.01 & 27.15 & 3.204 \\
\hline 2 & 0.002 & 4.02 & 54.30 & 3.196 \\
\hline 3 & 0.003 & 4.02 & 81.45 & 3.196 \\
\hline 4 & 0.004 & 4.02 & 108.61 & 3.196 \\
\hline 5 & 0.005 & 4.03 & 135.76 & 3.188 \\
\hline
\end{tabular}

Abbreviation: NTU, number of transfer unit.

TABLE 4 NTU, $M s_{\min }$, and $\tau$ for five levels of period $\beta$ (procedure $p=2$ )

\begin{tabular}{lcccc} 
Level & Period $\boldsymbol{\beta}(\mathbf{s})$ & NTU (-) & $\boldsymbol{M s}_{\min }(\mathbf{k g})$ & $\boldsymbol{\tau}\left(\mathbf{1 0}^{\mathbf{3}} \mathbf{s}\right)$ \\
\hline 1 & 4000 & 3.97 & 5.46 & 0.651 \\
2 & 8000 & 3.98 & 10.88 & 1.294 \\
\hline 3 & 12000 & 4.02 & 16.30 & 1.919 \\
4 & 16000 & 4.01 & 21.70 & 2.564 \\
5 & 20000 & 4.01 & 27.15 & 3.204 \\
\hline
\end{tabular}

Abbreviation: NTU, number of transfer unit.

TABLE $5 \mathrm{NTU}, M s_{\min }$, and $\tau$ for 14 levels of the designed rectifying duty $\theta_{\text {ran }(+)}$ (procedure $p=3$ )

\begin{tabular}{|lllll|}
\hline Level & $\theta_{\operatorname{ran}(+)}(-)$ & NTU (-) & $M_{\min }(\mathbf{k g})$ & $\tau\left(\mathbf{1 0}^{3} \mathbf{s}\right)$ \\
\hline 1 & 0.933 & 0.140 & 0.929 & 3.141 \\
\hline 2 & 0.867 & 0.280 & 1.927 & 3.257 \\
\hline 3 & 0.800 & 0.450 & 3.005 & 3.159 \\
\hline 4 & 0.733 & 0.620 & 4.177 & 3.187 \\
\hline 5 & 0.667 & 0.810 & 5.460 & 3.189 \\
\hline 6 & 0.600 & 1.010 & 6.879 & 3.223 \\
\hline 7 & 0.533 & 1.250 & 8.465 & 3.204 \\
\hline 8 & 0.467 & 1.520 & 10.263 & 3.195 \\
\hline 9 & 0.400 & 1.830 & 12.339 & 3.190 \\
\hline 10 & 0.333 & 2.200 & 14.795 & 3.182 \\
\hline 11 & 0.267 & 2.630 & 17.801 & 3.202 \\
\hline 12 & 0.200 & 3.210 & 21.675 & 3.195 \\
\hline 13 & 0.133 & 4.020 & 27.137 & 3.194 \\
\hline 14 & 0.067 & 5.400 & 36.477 & 3.196 \\
\hline
\end{tabular}

Abbreviation: NTU, number of transfer unit.

These three cases were selected because of proportional relations such as $\dot{m}_{1,2}=\dot{m}_{2,1}=2 \dot{m}_{1,1}$ and $\beta_{1}$, $\beta_{1}=\beta_{1,2}=5 \beta_{2,1}$. It can be noticed that the fluid outlet temperature was similar for the three cases, as well as for the HSM half plate length $(L / 2)$ temperature, meaning

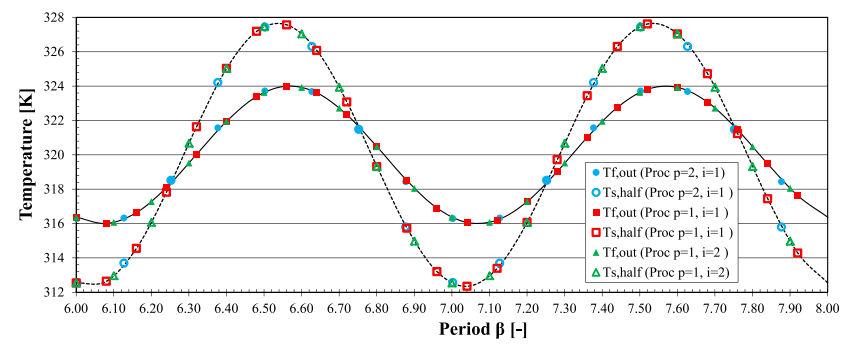

FIGURE 7 Time evolution of fluid outlet temperature $T_{f}$, out and HSM half plate length temperature $T_{s, \text { mid }}(L / 2)$ [Colour figure can be viewed at wileyonlinelibrary.com]

that the T3S optimization converged to the same optimal temperatures field for a given designed rectifying duty, eg, $\theta_{\text {ran (+) }}=0.133$. Looking back to Equations 3 and 4, it can be stated that any change in the parameters that compose NTU or $\tau$ demands the remaining ones to be changed in order to follow the same fluid and HSM half plate length temperatures. As an example, the HSM minimum mass was increased in a factor of 10 from $(p=2$; $i=1)$ to $(p=1 ; i=2)$, following the same behavior of the mass flow rate to period product. This observation allows to generalize the T3S behavior as a function of NTU and $\tau$.

Results for the designed rectifying duty $\theta_{\text {ran(+) }}$ (procedure $p=3$ ) are presented in Table 5 .

The smaller the designed rectifying duty $\theta_{\text {ran }(+)}$, the bigger amount of heat must be transferred by the HSM, making its minimum mass and NTU to increase. NTU is strongly dependent of $\theta_{\operatorname{ran}(+)}$, whereas $\tau$ is not, as its $3.5 \%$ deviation allows to consider it as constant.

\section{2 | Generalization}

Qualitative trends for NTU, $M s_{\min }$, and $\tau$ as a function of the mass flow rate $\dot{m}$, period $\beta$, and designed rectification duty $\theta_{\text {ran (+) }}$ are summarized in Table 6 .

Fitting curves were proposed to express the NTU (Equation 10) and $\tau$ (Equation 11) behavior of the T3S submitted to a sinusoidal temperature input.

$$
\begin{gathered}
\operatorname{NTU}\left(\theta_{\operatorname{ran}(+)}\right)=-1.996 \ln \left[\theta_{\operatorname{ran}(+)}\right], \\
\tau(\beta)=3196\left(\frac{\beta}{20000}\right) .
\end{gathered}
$$

With these fitting curves, any T3S under that input restriction can be designed to operate for a given $\theta_{\operatorname{ran}(+)}$, with the minimum HSM mass. Both NTU and $\tau$ followed a Pareto front, with an infinity combination of system parameters. In order to obtain the T3S geometry, based on fitting curves Equations 10 and 11, the next section 
TABLE 6 Qualitative behavior of NTU, $M s_{\min }$, and $\tau$ in respect to the T3S input parameters

\begin{tabular}{llll} 
Parameters & NTU (-) & Ms $\mathbf{m i n}(\mathbf{k g})$ & $\tau(\mathbf{s})$ \\
Mass flow rate $\dot{m}$ & Constant & Directly proportional & Constant \\
Period $\beta$ & Constant & Directly proportional & Directly proportional \\
Design rectifying duty $\theta_{\operatorname{ran}(+)}$ & Nonlinear association & Nonlinear association & Approx. constant \\
\hline
\end{tabular}

Abbreviations: NTU, number of transfer unit; T3S, sensible thermal energy storage system.

details a step-by-step sequence for the proposed design methodology. It is worth noticing that the fitting curves Equations 10 and 11 can be used to compose different designs methodologies.

\section{5 | STEP-BY-STEP SEQUENCE}

\section{1 | Input conditions}

Heat transfer coefficient $\bar{h}$ was calculated for the average laminar flow Nusselt correlation $\overline{N u}_{D_{h}}$ for infinite parallel flat plates, ${ }^{32,33}$ with air as the working fluid (Table 1):

$$
\begin{aligned}
\overline{N u}_{D_{h}}= & \left(\frac{\bar{h} D_{h}}{k_{f}}\right)_{j}=7.55 \\
& +\frac{0.024 L_{*}^{-1.14}}{1+0.0358 \operatorname{Pr}_{f}^{0.17} L_{*}^{-0.64}} \quad 0.1 \leq \operatorname{Pr}_{f} \leq 1000
\end{aligned}
$$

with the hydraulic diameter $D_{h}$, the dimensionless length $L *$ at the thermal entry region, and the Reynolds number $\mathrm{Re}_{D_{h}}$ defined by

$$
L^{*}=\frac{L}{D_{h} \operatorname{Re}_{D_{h}} \operatorname{Pr}_{f}}, \quad \text { with } D_{h}=2 e_{f} \text { and } \operatorname{Re}_{D_{h}}=\frac{\rho_{f} u_{f} D_{h}}{\mu_{f}}
$$

Figure 8 presents a three step-by-step sequence to find the T3S geometric dimensions (plate length $L$, thickness $e_{s}$, and distance $e_{f}$ ) according to operational conditions as mass flow rate $\dot{m}$, design rectifying duty $\theta_{\text {ran }(+)}$, and period $\beta$, for a given HSM.

First definition comes from setting the period $\beta$ and the design rectifying duty $\theta_{\operatorname{ran}(+)}$, which allows finding $\tau$ and NTU in Figure 9. Step 2 defines $\lambda=N T U c_{p, f} \dot{m}$, with the optimal value for NTU, air specific heat, and mass flow rate per channel.

Figure 10 allows selecting the optimal distance $e_{f}$, by the aid of $\lambda$ at the $x$ axis. Its value intercepts several plate length $L$ curves, and the chosen one gives the optimal distance $e_{f}$ at the $y$ axis.

Finally, step 3 aims to find the HMS volume $V_{s}=\tau \lambda / c_{p}$, ${ }_{s} \rho_{s}$, based on the optimal values of $\tau$ (step 1), $\lambda$ (step 2),

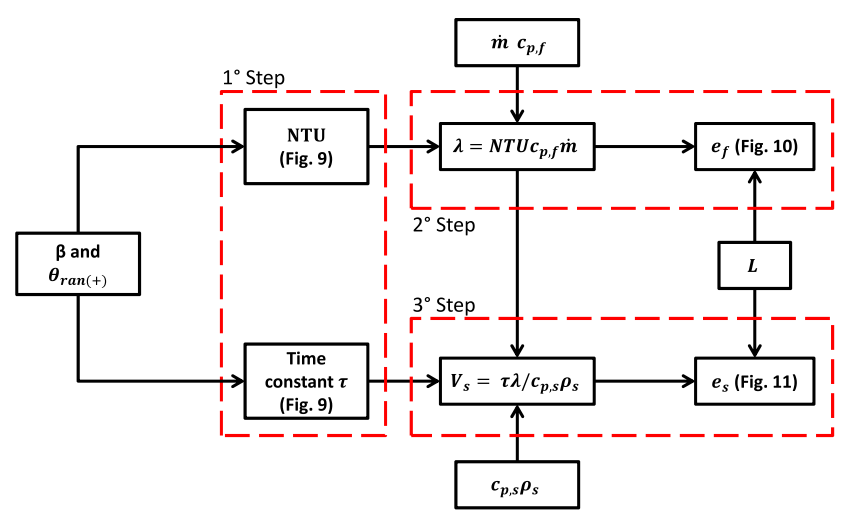

FIGURE 8 Proposed methodology to design a T3S [Colour figure can be viewed at wileyonlinelibrary.com]

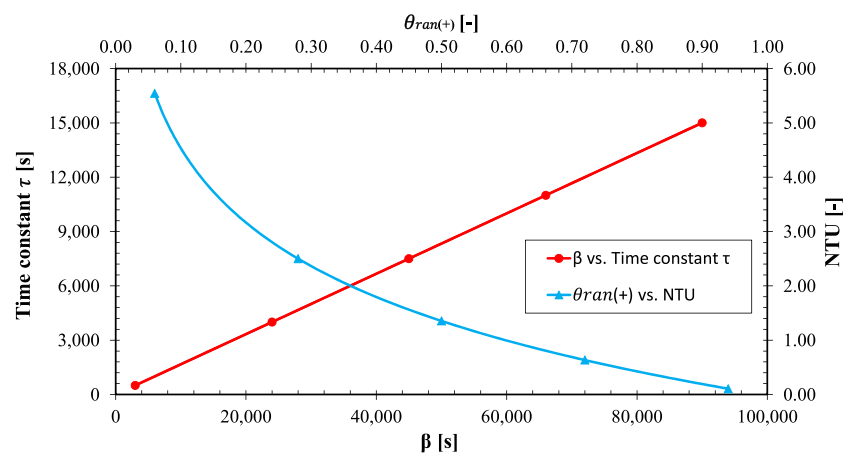

FIGURE 9 Time constant $\tau$ and NTU selection graph according to $\beta$ and $\theta_{\text {ran(+) }}$ settings [Colour figure can be viewed at wileyonlinelibrary.com]

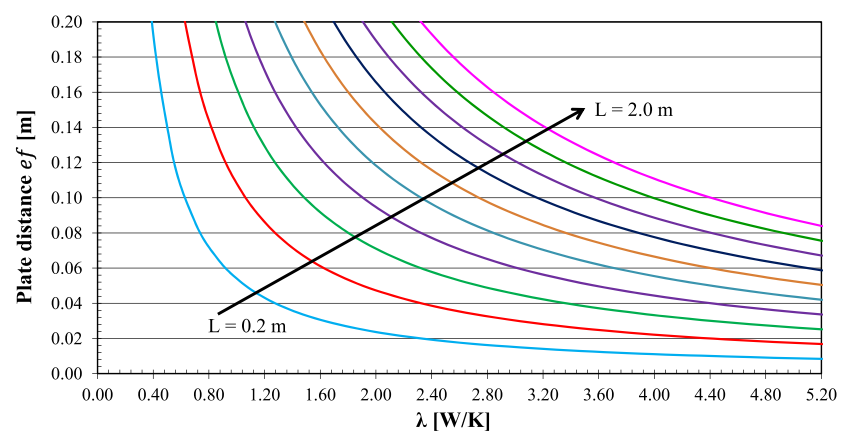

FIGURE 10 Plate distance $e_{f}$ selection graph as a function of the design parameter $\lambda$ and plate length $L$ [Colour figure can be viewed at wileyonlinelibrary.com] 
and material proprieties. Volume $V_{s}$ and plate length $L$ define the plate thickness $e_{s}$, as shown in Figure 11 .

All calculations may be performed with the aid of Equations 10 and 11, without the last three figures, but it will need the help of a nonlinear solution software. New figures must be built for working fluids different than air or for air properties different than those on Table 1, as the convective heat transfer correlations may change.

\section{2 | Case study}

Tests were proposed to give a methodology overview, compared with CFD simulations with STAR $\mathrm{CCM}+{ }^{34}$. That last software considers air proprieties as temperature dependent, as presented in Table 7. Specific heat was taken as constant due to its weak dependency for the simulated range of temperatures. Air properties for LEM were based on values from Table 1.

HSM density $\rho_{s}$ and HSM specific heat $c_{p}, s$ were defined for each test and then assumed as constant and uniform. HSM thermal conductivity $k$ was taken as unitary $\left(1 \mathrm{Wm}^{-1} \mathrm{~K}^{-1}\right)$, to respect LEM modeling restrictions ${ }^{17}$. Table 8 presents input data and operational conditions for three test cases.

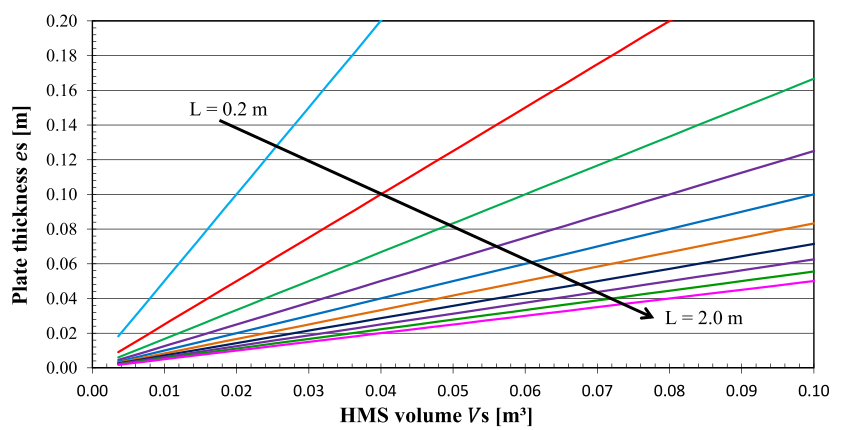

FIGURE 11 Plate thickness $e_{s}$ selection graph as a function of the HMS volume $V_{s}$ and plate length $L$ [Colour figure can be viewed at wileyonlinelibrary.com]

TABLE 7 Polynomial fit for air thermophysical properties for the temperature range of 150 to $3000 \mathrm{~K}^{\mathrm{a}}$

\begin{tabular}{|c|c|}
\hline Properties & Polynomial Fit \\
\hline Density $\rho_{f}\left(\mathrm{~kg} \mathrm{~m}^{-3}\right)$ & $345.57(T-2.6884)^{-1}$ \\
\hline $\begin{array}{l}\text { Thermal conductivity } \\
\qquad k_{f}\left(\mathrm{~W} \mathrm{~m}^{-1} \mathrm{~K}^{-1}\right)\end{array}$ & $\begin{array}{l}1.5797 \times 10^{-17} T^{5}+9.46 \times 10^{-14} T^{4} \\
\quad+2.2012 \times 10^{-10} T^{3}-2.3758 \times 10^{-7} \\
T^{2}+1.7082 \times 10^{-4} T-7.488 \times 10^{-3}\end{array}$ \\
\hline $\begin{array}{l}\text { Dynamic viscosity } \\
\qquad \mu_{f}\left(\mathrm{~kg} \mathrm{~m}^{-1} \mathrm{~s}^{-1}\right)\end{array}$ & $\begin{array}{l}2.5914 \times 10^{-15} T^{3}-1.4346 \times 10^{-11} T^{2} \\
\quad+5.0523 \times 10^{-8} T+4.1130 \times 10^{-6}\end{array}$ \\
\hline $\begin{array}{l}\text { Specific heat } \\
\qquad c_{p, f}\left(\mathrm{~J} \mathrm{~kg}^{-1} \mathrm{~K}^{-1}\right)\end{array}$ & Constant; 1008 \\
\hline
\end{tabular}

${ }^{\mathrm{a} Z o g r a f o s}$ and Martin. ${ }^{35}$
T3S dimensions are reported in Table 9, calculated by the proposed design methodology.

Results in respect to the maximal outlet temperature are presented in Table 10. All results displayed relative deviations below $1.5 \%$.

TABLE 8 Performed test cases for LEM and CFD comparison

\begin{tabular}{llll} 
T3S Operation Parameters & Test 1 & Test 2 & Test 3 \\
\hline Mass flow $\dot{m}\left(\mathrm{~kg} \mathrm{~s}^{-1}\right)$ & 0.002 & 0.002 & 0.008 \\
\hline Inlet sine period $\beta(\mathrm{s})$ & 4000030000 & 30000 \\
\hline $\begin{array}{l}\text { Senoid central temperature } T_{m}(\mathrm{~K}) \\
\text { Inlet senoid upper temperature } T_{f, \text { in }(+)}\end{array}$ & 320.00 & 350.00 & 400.00 \\
\hline $\begin{array}{l}\text { Designed outlet senoid upper } \\
\quad \text { temperature } T_{\text {ran }(+)}\end{array}$ & 340.00 & 353.00 & 430.00 \\
\hline $\begin{array}{llll}\text { HSM density } \rho_{\mathrm{s}}\left(\mathrm{kg} \mathrm{m}^{-3}\right) \\
\text { HSM specific heat }\end{array}$ & 1000 & 2000 & 3000 \\
\hline
\end{tabular}

$c_{p, s}\left(\mathrm{~J} \mathrm{~kg}_{-1} \mathrm{~K}_{-1}\right)$

Abbreviations: CFD, computer fluid dynamics; LEM, lumped element model; T3S, sensible thermal energy storage system.

TABLE 9 Parameters and dimensions for the three test cases calculated by the proposed design methodology

\begin{tabular}{|c|c|c|c|}
\hline & Test 1 & Test 2 & Test 3 \\
\hline \multicolumn{4}{|l|}{ T3S dimensions } \\
\hline Plate length $L(\mathrm{~m})$ & 0.4 & 0.8 & 1.0 \\
\hline Plate distance $e_{f}(\mathrm{~m})$ & 0.0248 & 0.0364 & 0.0466 \\
\hline Plate thickness $e_{s}(\mathrm{~m})$ & 0.06756 & 0.0363 & 0.02545 \\
\hline \multicolumn{4}{|l|}{ T3S parameters } \\
\hline $\begin{array}{l}\text { Dimensionless temperature } \\
\theta_{\operatorname{ran}(+)}(-)\end{array}$ & 0.4 & 0.3 & 0.75 \\
\hline NTU (-) & 1.789 & 2.34 & 0.57 \\
\hline Time constant $\tau(\mathrm{s})$ & 6,684 & 4,912 & 5,000 \\
\hline$\lambda\left(\mathrm{W} \mathrm{K}^{-1}\right)$ & 3.606 & 4.717 & 4.596 \\
\hline$V_{s}\left(\mathrm{~m}^{3}\right)$ & 0.02678 & 0.02896 & 0.02553 \\
\hline
\end{tabular}

Abbreviations: T3S, sensible thermal energy storage system.

TABLE 10 Values for the design maximal outlet temperature and the ones predicted from LEM and CFD methods for the three test cases

\begin{tabular}{llll} 
Maximal Outlet Temperature & Test 1 & Test 2 & Test 3 \\
\hline Design & 340.00 & 353.00 & 430.00 \\
\hline LEM & 339.42 & 352.99 & 429.80 \\
\hline CFD & 340.33 & 353.10 & 430.48 \\
\hline
\end{tabular}

Abbreviations: CFD, computer fluid dynamics; LEM, lumped element model. 


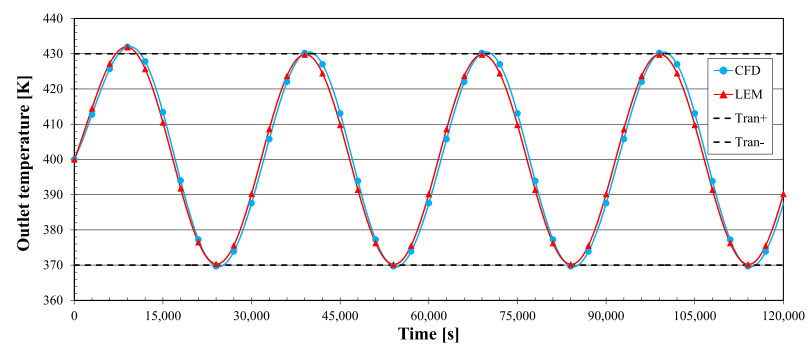

FIGURE 12 T3S outlet air temperature $T_{f}$, out for test 3 from lumped element model (LEM) and computer fluid dynamics (CFD) simulation [Colour figure can be viewed at wileyonlinelibrary.com]

Figure 12 brings test 3 results to show how the T3S proposed design methodology arrived to ensure the rectifying capacity duty.

Results presented very little deviation from CFD, LEM, and the rectifying capacity duty and showed the suitability of the proposed design methodology to simulate heat storage under cyclic conditions, within the method validity range.

\section{6 | CONCLUSIONS}

This paper presented and discussed a methodology to design T3S based on LEMs, which meant to work as a thermal rectifier. LEM is a simplified and low time consuming approach that can replace more sophisticated ones, like CFD solutions, within a range of well-known restrictions.

The T3S was composed by a set of flat parallel plates, the HSM, separated by narrow channels, where an induced fluid stream carries the exchanged energy of the system. A sinusoidal cyclic inlet temperature flow was imposed to the system, and a continuous outlet was obtained within a narrow limit range of temperature values, which characterized the system as a thermal rectifier.

The methodology was based on inverse design approach and searched for the minimization of the HSM mass capable to restrain the outlet temperature to the operational range. The optimization algorithm implies on a large number of calls of the user function, also known as the direct solution, which is time consuming, especially if that direct solution was based on CFD models, and justified the search for more rapid but still accurate models, like LEM. The analysis revealed that the NTU and time constant $\tau$ can describe the T3S thermal behavior, whose respective dependency are the design rectifying duty and the inlet temperature period.

A step-by-step sequence to the proposed design methodology was presented and detailed. Any future user can choose from using fitted curves for NTU and time constant $\tau$ calculation, together with some extra relations, or follow a sequence of detailed graphs to reach the T3S design that respects the operational outlet temperature range.

The proposed design methodology solution was compared with CFD simulations, and results showed little deviations among them, whenever LEM respected the modeling restrictions, with values below $1.5 \%$ for the tested cases.

In conclusion, any T3S operating as a thermal rectifier, submitted to a sinusoidal cyclic temperature input and with constant and uniform HSM and fluid properties, can be designed with the NTU and $\tau$ fitting curves. The resulting T3S configuration will guarantee the outlet fluid temperature within the operational range using the minimum HSM mass.

\section{ACKNOWLEDGEMENTS}

Andriotty acknowledges CAPES (Brazilian Coordination for the Improvement of Higher Education Personnel) for his doctorate grant, and Smith Schneider acknowledges CNPq (Brazilian National Council for Scientific and Technological Development) for the research grant (CNPq-PQ 305357/2013-1).

\section{NOMENCLATURE}

$A_{s} \quad$ solid-fluid interface area, $\mathrm{m}^{2}$

$c_{p} \quad$ specific heat, $\mathrm{J} \mathrm{kg}^{-1} \mathrm{~K}^{-1}$

$D_{h} \quad$ hydraulic diameter, $\mathrm{m}$

$e_{f} \quad$ plate distance, $m$

$e_{s} \quad$ plate thicknesses, $\mathrm{m}$

$\bar{h} \quad$ average heat transfer coefficient, $\mathrm{W} \mathrm{m}^{-2} \mathrm{~K}^{-1}$

$\mathrm{j} \quad$ generic section

$k$ thermal conductivity, $\mathrm{W} \mathrm{m}^{-1} \mathrm{~K}^{-1}$

$L \quad$ plate length, $\mathrm{m}$

$L_{*} \quad$ dimensionless length at the thermal entry region

$\dot{m} \quad$ air mass flow rate, $\mathrm{kg} \mathrm{s}^{-1}$

Ms HSM mass

Mf working fluid mass

$n \quad$ total number of independent sections

$\mathrm{N} \quad$ last section

$\overline{N u}_{D_{h}}$ average Nusselt correlation for parallel flat plates

$\mathrm{p} \quad$ procedure

Pr Prandtl number

$R_{p} \quad$ optimal result matrix

$\operatorname{Re}_{D_{h}} \quad$ Reynolds number

$t$ time, $\mathrm{s}$

$T \quad$ temperature, $\mathrm{K}$ 


$\begin{array}{ll}\bar{T}_{f, j}(t) \quad \begin{array}{l}\text { fluid temperature mean value in respect to } \\ (j-1) \text { section, } \mathrm{K}\end{array} \\ u & \text { velocity, } \mathrm{m} \mathrm{s}^{-1} \\ V & \text { volume, } \mathrm{m}^{3} \\ W & \text { unitary width, } \mathrm{m} \\ x & \text { axial direction } \\ y & \text { transversal direction }\end{array}$

\section{GREEK SYMBOLS}

$\mu \quad$ dynamic viscosity, Pa.s

$\beta \quad$ cycle period, $s$

$\rho$ density, $\mathrm{kg} \mathrm{m}^{-3}$

$\tau \quad$ time constant, $\mathrm{s}$

$\Delta t$ time step, $\mathrm{s}$

$\theta$ dimensionless temperature, rectifying capacity

$\lambda$ design parameter, $\mathrm{W} \mathrm{K}^{-1}$

\section{SUBSCRIPTS}

$\begin{array}{ll}f & \text { fluid } \\ \text { in } & \text { inlet } \\ + & \text { upper limit } \\ - & \text { lower limit } \\ m & \text { periodic mean value } \\ \text { oper } & \text { operational } \\ \text { out } & \text { outlet } \\ \text { ran } & \text { range } \\ s & \text { solid }\end{array}$

\section{ABBREVIATIONS}

CFD computer fluid dynamics

HSM heat storage material

LEM lumped element model

NTU number of transfer unit

PCM phase change material

T3S sensible thermal energy storage system

\section{ORCID}

Tiago Haubert Andriotty (D) https://orcid.org/0000-00021859-034X

Paulo Smith Schneider (D) http://orcid.org/0000-0002-66676156

Leticia Jenisch Rodrigues (1) https://orcid.org/0000-00028147-0770

\section{REFERENCES}

1. Klein SA, Beckman WA, Duffie JA. A design procedure for solar heating systems. Sol Energy. 1976;18(2):113-127.

2. Schmidt FW, Szego J. Transient response of solid sensible heat thermal storage units-single fluid. J Heat Transfer. 1976;98: 471-477.

3. Schmidt FW, Somers RR, Szego J, Laananen DH. Design optimization of a single fluid, solid sensible heat storage unit. $J$ Heat Transfer. 1977;99(2):174-179.

4. Li P, Van Lew J, Chan C, Karaki W, Stephens J, O'Brien JE. Similarity and generalized analysis of efficiencies of thermal energy storage systems. Renew Energy. 2012;39(1):388-402.

5. Jian Y, Falcoz Q, Neveu P, Bai F, Wang Y, Wang Z. Design and optimization of solid thermal energy storage modules for solar thermal power plant applications. Appl Energy. 2015;139:30-42.

6. Gude VG, Nirmalakhandan N, Deng S, Maganti A. Low temperature desalination using solar collectors augmented by thermal energy storage. Appl Energy. 2012;91(1):466-474.

7. Darzi AR, Moosania SM, Tan FL, Farhadi M. Numerical investigation of free-cooling system using plate type PCM storage. Int Commun Heat Mass Transfer. 2013;48:155-163.

8. Zanganeh G, Commerford M, Haselbacher A, Pedretti A, Steinfeld A. Stabilization of the outflow temperature of a packed-bed thermal energy storage by combining rocks with phase change materials. Appl Therm Eng. 2014;70(1):316-320.

9. Soda M, Beyene A. Multiphase ultra-low grade thermal energy storage for organic Rankine cycle. Int J Energy Res. 2016;40(1): 51-60.

10. Rezaie B, Reddy BV, Rosen MA. Thermodynamic analysis and the design of sensible thermal energy storages. Int $J$ Energy Res. 2017;41(1):39-48.

11. Ghoreishi-Madiseh SA, Sasmito AP, Hassani FP, Amiri L. Performance evaluation of large scale rock-pit seasonal thermal energy storage for application in underground mine ventilation. Appl Energy. 2017;185:1940-1947.

12. Demir ME, Dincer I. Development and analysis of a new integrated solar energy system with thermal storage for fresh water and power production. Int J Energy Res. 2018;42: 2864-2874. https://doi.org/10.1002/er.3846

13. Hasnain SM. Review on sustainable thermal energy storage technologies, Part I: heat storage materials and techniques. Energ Conver Manage. 1998;39(11):1127-1138.

14. Flueckiger SM, Iverson BD, Garimella SV, Pacheco JE. Systemlevel simulation of a solar power tower plant with thermocline thermal energy storage. Appl Energy. 2014;113:86-96.

15. Pelay U, Luo L, Fan Y, Stitou D, Rood M. Thermal energy storage systems for concentrated solar power plants. Renew Sustain Energy Rev. 2017;79:82-100.

16. Lefebvre D, Tezel FH. A review of energy storage technologies with a focus on adsorption thermal energy storage processes for heating applications. Renew Sustain Energy Rev. 2017;67: 116-125.

17. Andriotty TH, Inverse design methodology applied to design sensible thermal energy storage systems. Doctoral thesis 2018, Federal University of Rio Grande do Sul. 
18. Duffie JA, Beckman WA. Solar engineering of thermal processes. New Jersey: John Wiley \& Sons; 2013:910.

19. Maithani R, Patil AK, Saini JS. Investigation of effect of stratification on the thermal performance of packed bed solar air heater. Int J Energy Sci. 2013;3(4).

20. Mawire A, Mcpherson M, Van Den Heetkamp RRJ, Mlatho SJP. Simulated performance of storage materials for pebble bed thermal energy storage (TES) systems. Appl Energy. 2009;86(7): 1246-1252.

21. Mumma SA, Marvin WC. A method of simulating the performance of a pebble bed thermal energy storage and recovery system. American Society of Mechanical Engineers and American Institute of Chemical Engineers, Heat Transfer Conference 1976;Aug. 9-11, apud Singh et al., 2009.

22. Singh R, Saini RP, Saini JS. Models for predicting thermal performance of packed bed energy storage system for solar air heaters- a review. Open Fuels Energy Sci J. 2009;2:47-53.

23. Çengel AY. Heat and mass transfer: fundamentals and applications. New York: McGraw-Hill; 2011:902.

24. Hughes PJ. The design and predicted performance of Arlington House. Master thesis 1975, University of Wisconsin-Madison.

25. Bergman TL, Incropera FP, Dewitt DP, Lavine AS. Fundamentals of heat and mass transfer. New Jersey: John Wiley \& Sons; 2011:1048.

26. Stiglitz JE. Pareto optimality and competition. J Financ. 1981;36(2):235-251.

27. Luenberger DG. New optimality principles for economic efficiency and equilibrium. J Optim Theory Appl. 1992;75(2): 221-264.
28. Tomoiagă B, Chindriş M, Sumper A, Sudria-Andreu A, Villafafila-Robles R. Pareto optimal reconfiguration of power distribution systems using a genetic algorithm based on NSGA-II. Energies. 2013;6(3):1439-1455.

29. Montgomery DC. Design and Analysis of Experiments, 8th edition. New Jersey: John Wiley \& Sons; 2013 Chapter 11.724 p.

30. Sun W, Yuan YX. Optimization theory and methods: nonlinear programming. New York: Springer Science \& Business Media; 2006:687.

31. Boyd S, Vandenberghe L. Convex optimization. Cambridge: Cambridge university press; 2004:716.

32. Stephan K. Wärmeübergang und Druckabfall bei nicht ausgebildeter Laminarströmung in Röhren und ebenen Spalten. Chen Int Tech. 1959;31:773-778. apud Bejan A, 2004

33. Bejan A. Convection Heat Transfer. 4th ed. New Jersey: John Wiley \& Sons; 2013:685.

34. STAR-CCM+ Manual. CD Adapco 2017.

35. Zografos AI, Martin WA, Sunderland JE. Equations of properties as a function of temperature for seven fluids. Comput Methods Appl Mech Eng. 1987;61(2):177-187.

How to cite this article: Andriotty TH, Smith Schneider P, Jenisch Rodrigues L. Inverse design methodology to optimize sensible thermal energy storage systems working as rectifiers. Int J Energy Res. 2019;43:6442-6453. https://doi.org/10.1002/ er.4463 